\title{
Polyvinyl Alcohol Hydrogel Irradiated and Acetalized for Osteochondral Defect Repair: Mechanical, Chemical, and Histological Evaluation after Implantation in Rat Knees
}

\author{
N. A. Batista, ${ }^{1}$ A. A. Rodrigues, ${ }^{1}$ V. P. Bavaresco, ${ }^{2}$ J. R. L. Mariolani, ${ }^{1}$ and W. D. Belangero ${ }^{1}$ \\ ${ }^{1}$ Orthopaedic Biomaterials Laboratory, Faculty of Medical Sciences, University of Campinas (UNICAMP), \\ Rua Tessália Vieira de Camargo, no. 126, Cidade Universitária “Zeferino Vaz”, 13083-887 Campinas, SP, Brazil \\ ${ }^{2}$ Department of Plastic, Technical College Campinas (COTUCA), University of Campinas (UNICAMP), 13083-887 Campinas, \\ SP, Brazil
}

Correspondence should be addressed to N. A. Batista, nbatista@fcm.unicamp.br

Received 10 March 2012; Revised 20 August 2012; Accepted 12 September 2012

Academic Editor: Frank Feyerabend

Copyright ( $) 2012$ N. A. Batista et al. This is an open access article distributed under the Creative Commons Attribution License, which permits unrestricted use, distribution, and reproduction in any medium, provided the original work is properly cited.

\begin{abstract}
Polyvinyl Alcohol (PVA) hydrogel plugs were implanted in artificial osteochondral defects on the trochlear groove of rat knees. After $0,3,6,12$, and 24 weeks of followup, samples containing the implants were mechanically evaluated by creep indentation test, chemically, and histologically by optical microscopy. The mechanical test pointed towards an increase of the implant creep modulus and the chemical analysis exhibited an increasing concentration of calcium and phosphorus within the implants over time. Optical microscopy showed no foreign body reaction and revealed formation, differentiation, and maintenance of new tissue at the defect/implant interface. The absence of implant wear indicated that the natural articular lubrication process was not disturbed by the implant. The performance of the irradiated and acetalized PVA was considered satisfactory for the proposed application.
\end{abstract}

\section{Introduction}

The articular cartilage consists of a high-specialized, low friction tissue that covers the epiphyses with the function of enabling bones do glide over each other and to absorb impacts within the joint without causing wear; this cartilage has a poor capacity of renewal [1-3]. Its viscoelastic behavior depends on the intrinsic mechanical properties of the extracellular matrix, the presence of collagen gel in the matrix, and the flow of the interstitial water due to the load applied during the movement $[4,5]$.

The articular cartilage can suffer degeneration, beginning with a degradation of the cartilage itself (chondral lesion) that may reach and expose the subchondral bone (osteochondral lesion) [6]. The damages can be of traumatic origin, such as articular fractures, ligament, or meniscus lesions, or of inflammatory origin, as in autoimmune or metabolic diseases [7]. The Articular Cartilage exhibits a low-intrinsic ability of self-repair, this is due to a lack of vascularization and due to the low-metabolic activity of the mature chondrocytes, which in turn, limit the supply of growth factors, responsible for the cellular differentiation and proliferation [2]. Furthermore, the lack of innervation delays the manifestation of clinical symptoms, facilitating a quiet advance of the articular degeneration [8].

Nowadays, treatment options are based on abrasion, microfractures, mosaicplasty, first- and second-generation autologous chondrocyte implantation, and allogeneic osteochondral grafting [9-16]. These techniques have drawbacks such as morbidity of the donor area, reduced mechanical stability of the new tissue compared with the normal cartilage, genetic incompatibility between donor and recipient and high cost, among other problems, and none of these have so far proven to be effective enough to ensure complete longterm regeneration [17].

In view of this, the development of osteochondral implants that mimic the physical, chemical, and mechanical properties of the articular cartilage has been proposed [4, 


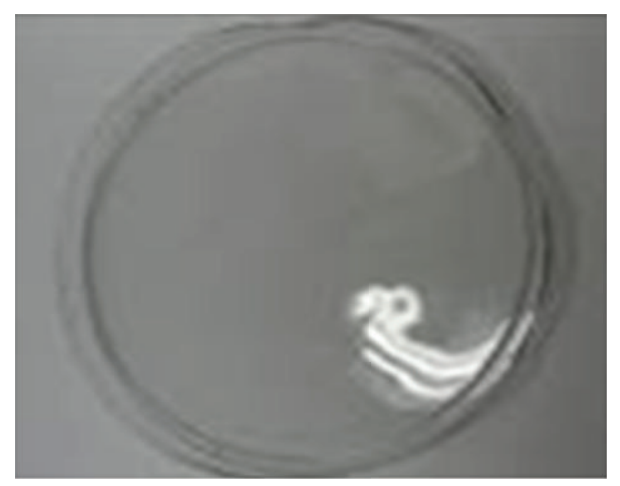

Figure 1: PVA membrane.

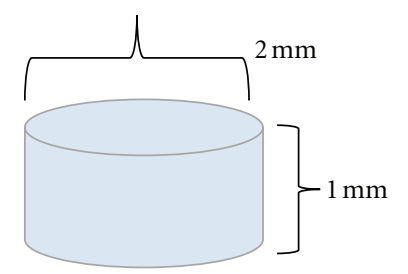

FIgURE 2: Osteochondral implant PVA.

17, 18]. Such implants for osteochondral defects consist of scaffolds that must allow simultaneous growth of both cartilage tissue and subchondral bone. They may neither be cytotoxic nor elicit inflammatory response of the host tissue; otherwise they will not allow cartilage regeneration and will be encapsulated by fibrous tissue.

Among the materials used for osteochondral defect repair, bioceramics, such as bioglass, hydroxyapatite, and calcium phosphate, occupy a prominent place [18]. Noteworthy is also the use of synthetic biodegradable polymers such as $\operatorname{poly}(\alpha$-hydroxy ester), poly(ethylene glycol) (PEG), and poly (caprolactone) (PCL) [19]. These polymers exhibit the advantages of easy processing, low-processing costs, controlled biodegradability, and FDA-approval [20]. Amongst them, the polymeric hydrogels have proven to be a promising class of materials for osteochondral repair, since their physical and chemical characteristics can resemble that of the articular cartilage and the subchondral bone $[4,21-$ 26]. Polyvinyl alcohol (PVA) crosslinked by electron beam irradiation deserves special attention thanks to its chemical stability against biological fluids, good elasticity, adequate mechanical strength, hydrophilicity, physical properties similar to those of the cartilage, and low processing costs [2730].

Preliminary in vitro and in vivo tests of PVA hydrogel have exhibited promising results [31, 32], qualifying PVA for further tests. Thus, the aim of this study was to evaluate the in vivo performance of PVA cross-linked by electron beam irradiation implanted in Wistar rats' knees by means of mechanical, chemical, and histological tests.

\section{Materials and Methods}

2.1. Preparation and Characterization of Polyvinyl Alcohol (PVA). Aqueous solution of PVA was obtained by $10 \%$ Sigma-Aldrich mW 89,000-98,000 g/mol, 99\% hydrolyzed and was prepared and homogenized at $70^{\circ} \mathrm{C}$ for $1 \mathrm{~h}$ in magnetic stirrer. The solution was transferred to a Petri dish and kept at room temperature for 7 days resulting in $1 \mathrm{~mm}$ thick membranes (Figure 1). The membranes were acetalised by a chemical treatment composed of formaldehyde solution 40\% (w/w) (Aldrich), concentrated sulfuric acid 50\% (w/w) (Aldrich), and $300 \mathrm{~g}$ anhydrous sodium sulfate (Aldrich). The membranes were maintained in this solution under constant stirring at $70^{\circ} \mathrm{C}$ for $24 \mathrm{~h}$. After being washed and hydrated in running distilled water, the samples were crosslinked by electron beam irradiation at 25 kGy produced by a Radiation Dynamiton electron beam accelerator (Institute of Energy and Nuclear Research, São Paulo, Brazil) [32].

Thereafter, the samples were hydrated and swelled in $0.9 \%$ sodium chloride $(\mathrm{NaCl})$ solution for $48 \mathrm{~h}$ and osteochondral implants (plugs $2 \mathrm{~mm}$ in diameter and $1 \mathrm{~mm}$ in height) were obtained by punched cut outs (Figure 2). The plugs were stored at low temperature in sterile Falcon tubes containing $0.9 \% \mathrm{NaCl}$ until implantation.

2.2. Animal Care and Experimental Groups. Forty-four male rats $(\sim 380 \mathrm{~g})$ were anesthetized by intravenous injection of $25 \mathrm{mg} / \mathrm{kg}$ pentobarbital according to the ethical protocol approved by the Ethics Committee in Animal Experimentation of the University of Campinas, São Paulo, Brazil (proto$\mathrm{col} \mathrm{n}^{\circ}$ 1047-1/2008). The knee joint was accessed by a medial parapatellar incision and a twist drill fitted with a depth stop was used to produce cylindrical osteochondral defects $(2 \mathrm{~mm}$ in diameter and $1 \mathrm{~mm}$ deep) in the intercondylar region.

The animals were divided into 6 groups: 5 experimental groups with 8 animals each, for implantation of the PVA samples $(0,3,6,12$, and 24 weeks followup referred to as EG00, EG03, EG06, EG12, and EG24, resp.) and a "cartilage" control group (CG) with 08 animals, whose articular cartilage was kept intact.

2.2.1. Surgical Procedures and Experimental Design. The hydrogel plugs were inserted under pressure into the defects with the aid of a trephine and sit flush with the surface of the adjacent articular cartilage (Figure 3 ). The joint capsule and the skin were sutured and the animals were placed in cages where they received Paracetamol solution $25 \mathrm{mg} / \mathrm{kg}$ for $24 \mathrm{~h}$. After that, only food and water were offered ad libitum until the animals were sacrificed.

2.3. Creep Indentation Test (CIT). Six condyles from each EG and CG group $(n=36)$ were randomly selected and stored in $0.9 \% \mathrm{NaCl}$ solution until the test, in order to avoid tissue autolysis. The test was carried out on a universal testing machine EMIC DL300 (Curitiba, Brazil). A load of $4.905 \mathrm{~N}(0.5 \mathrm{kgf})$ was applied to the implant surface by a hemispherically ended indenter ( $1.4 \mathrm{~mm}$ diameter $)$ and kept 


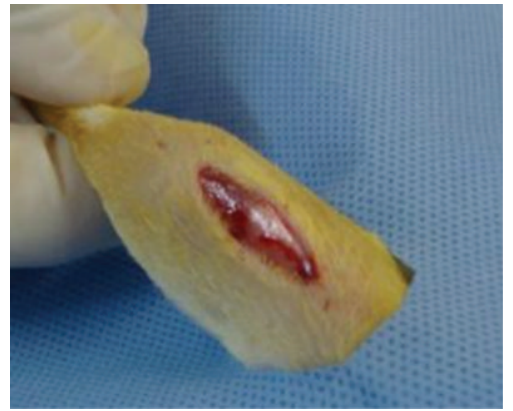

(a)

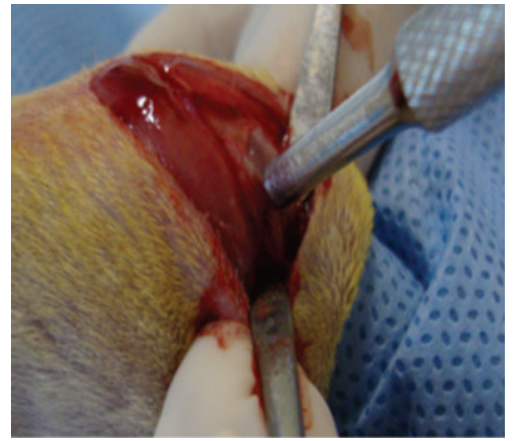

(d)

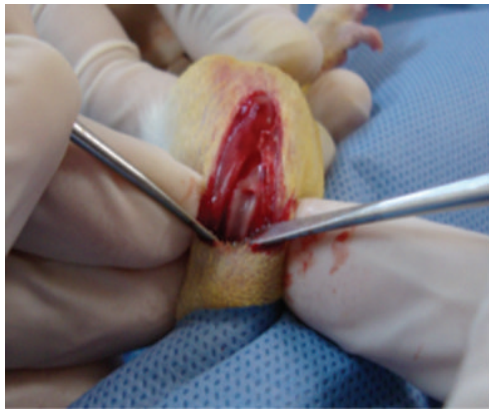

(b)

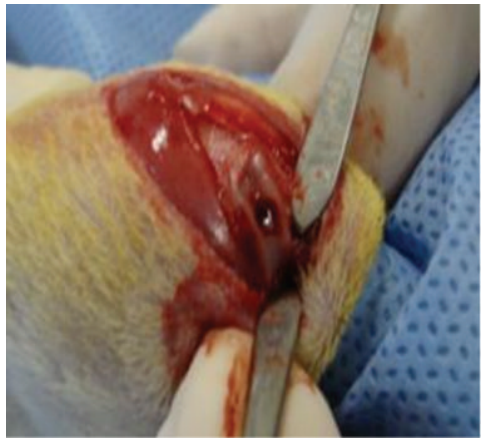

(e)



(c)

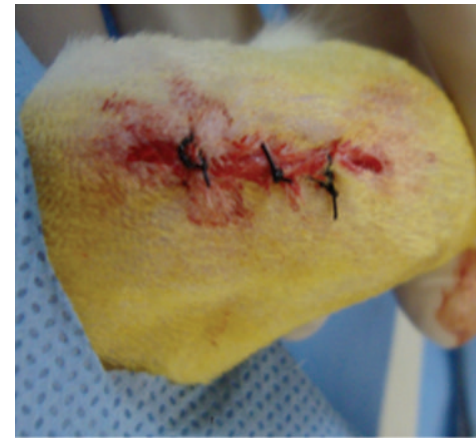

(f)

FIGURE 3: Surgical procedure: (a) skin incision; (b) exposure of the intercondylar region; (c) drilling the osteochondral defect with a 2 mm diameter and $1 \mathrm{~mm}$ depth stop; (d) PVA implant; (e) defect filled with the PVA implant; (f) suture.

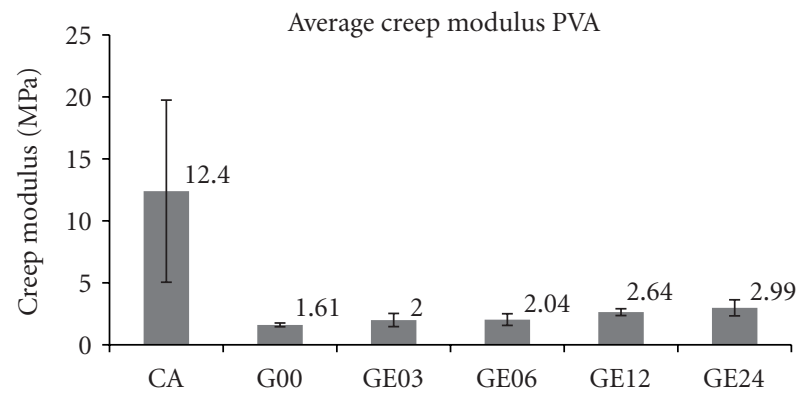

Figure 4: Average creep modulus and respective standard deviations for the rat articular cartilage (CA), control group (G00), and the experimental groups (EGs) according to follow-up time. Confidence level $(P<0.05)$ was obtained through Anova multiple comparison analysis statistics.

for 180 seconds [33] and curves of indenter penetration depth versus time were plotted from test data that were continuously registered by the test machine software (TESC 3.04). The creep modulus for the hydrogels in situ at 180 seconds after load application was calculated according to the equation below (originally deduced for sheets of vulcanized rubber and successfully used by Kempson et al. [34] for human articular femoral cartilage):

$$
\begin{gathered}
E=\frac{9 \times 10^{-6} p}{16 \sqrt{r}}\left[\frac{1-e^{(-0.42 t / a)}}{h}\right]^{3 / 2}, \\
a=\sqrt{\left(2 r h-h^{2}\right)}[\mathrm{m}] .
\end{gathered}
$$

2.4. X-Ray Fluorescence Analysis (EDXRF). Three hydrogel plugs from each EG $(n=12)$ and three nonimplanted plugs EG00 $(n=3)$ were subjected to XRF analysis, in order to assess the incorporation of calcium $(\mathrm{Ca})$, phosphorus $(\mathrm{P})$, and sulfur (S) by the PVA. After removal, the plugs were dried at room temperature, put into XRF polyethylene sample cups (Chemplex), and analyzed on an energy dispersive Xray fluorescence spectrometer (Shimadzu EDX 700) with rhodium X-ray tube and semiconductor $\mathrm{Si}(\mathrm{Li})$ detector (energy resolution of $165 \mathrm{eV}$ (Mn Ka line), under the following conditions: $3 \mathrm{~mm}$ diameter incident beam collimator, $\mathrm{X}$ ray tube voltage of $15 \mathrm{kV}$, exposure time of $100 \mathrm{~s}$, and detector dead time of $25 \%[35,36]$. The software AXIL was employed 


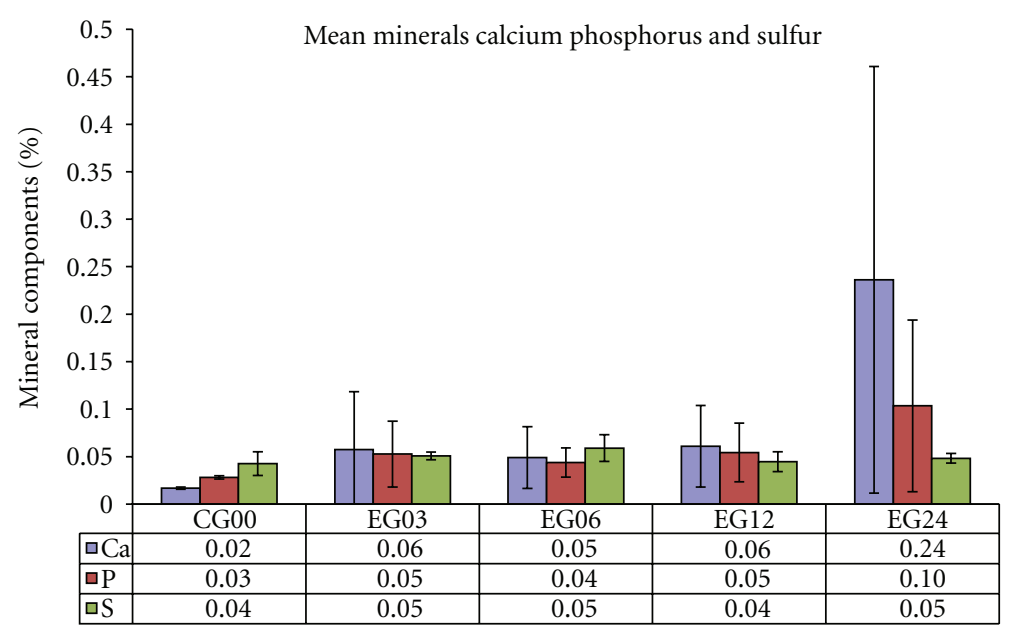

FIGURE 5: Mean concentrations of calcium, phosphorus, and sulphur found in the implanted plugs according to follow-up time (EGs) and PVA not implanted in vivo (GC00). Confidence level $(P<0.05)$ was obtained through Anova multiple comparison analysis statistics.

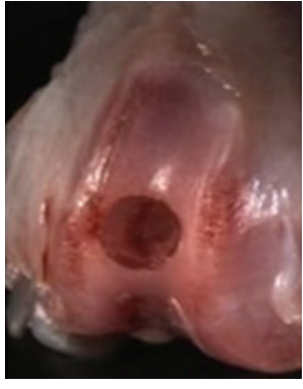

EG03

(a)



EG06

(b)



EG12

(c)

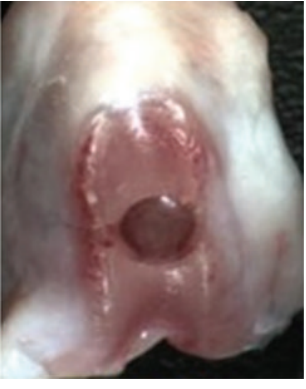

EG24

(d)

FIGURE 6: EGs stereoscopic images. Maintenance of PVA aspect and of adjacent cartilage can be observed, furthermore there was an absence of neoformed tissue surrounding the implant and no PVA implant collapse. Magnification 10x.

TABLE 1: Criteria and score evaluation by GE's optical microscopy.

\begin{tabular}{ll}
\hline Evaluated criteria & \multicolumn{1}{c}{ Scores } \\
\hline Granulation tissue $(\mathrm{GT})$ & \\
Collagen fibers $(\mathrm{CF})$ & Absent $(+)$ \\
Mineralized bone matrix $(\mathrm{MB})$ & Moderate $(++)$ \\
Neoformed bone tissue (NB) & Intensive $(+++)$ \\
Collapse of neoformed tissue $(\mathrm{CN})$ & \\
\hline
\end{tabular}

to interpret the results and calculate the concentration of the elements in the samples.

2.5. Optical Microscopy (OM). After the mechanical test, fourteen samples from the EG group $(n=40)$ were fixed in buffered $10 \%$ formaldehyde solution $(\mathrm{pH} 7.5)$ for $48 \mathrm{~h}$, decalcified in a solution of ethylenediaminetetraacetic acid disodium (EDTA) 7\% (w/w), hydrochloric acid 100\% $140 \mathrm{~mL}(\mathrm{w} / \mathrm{w})$, sodium tartarate $0.15 \%$ (w/w), sodium, and kaulium tartarate $0.9 \%(\mathrm{w} / \mathrm{w})$ in distilled water for
15 days, washed in distilled water for removal of residual decalcifying solution, immersed in ethanol $70 \%$, and finally embedded in paraffin. The samples were prepared for OM according to the previously described protocol [23].

Semithin serial sections ( $4 \mu \mathrm{m}$ thick) were cut on a rotatory microtome Leica 2155 and stained with hematoxylin eosin (HE). Images were obtained with a Leica DMLB $100 \mathrm{~S}$ microscope (magnification $200 \mu \mathrm{m}$ ). The images were analyzed for the absence, moderate, or intensive presence of the following structures: granulation tissue (GT), collagen fibers (CF), mineralized bone matrix $(\mathrm{MB})$, neoformed bone tissue (NB), and collapse of neoformed tissue $(\mathrm{CN})$.

The results obtained by $\mathrm{OM}$ were evaluated according to the criteria: absent $(+)$, moderate $(++)$, and $(+++)$ intensive as described in Table 1.

\section{Results}

3.1. Creep Indentation Test (CIT). Figure 4 shows the average creep modulus and respective standard deviation for each experimental control group. 


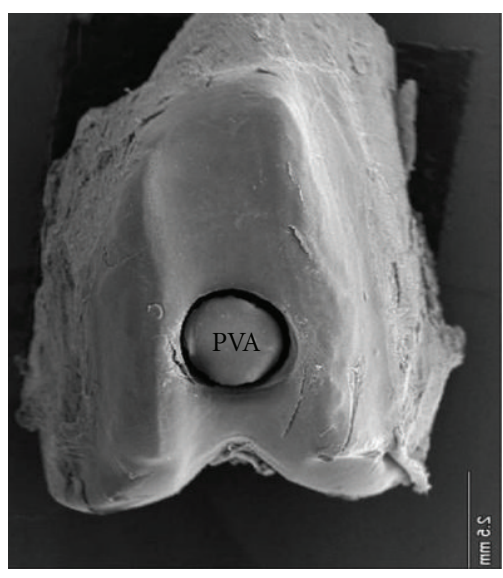

(a)

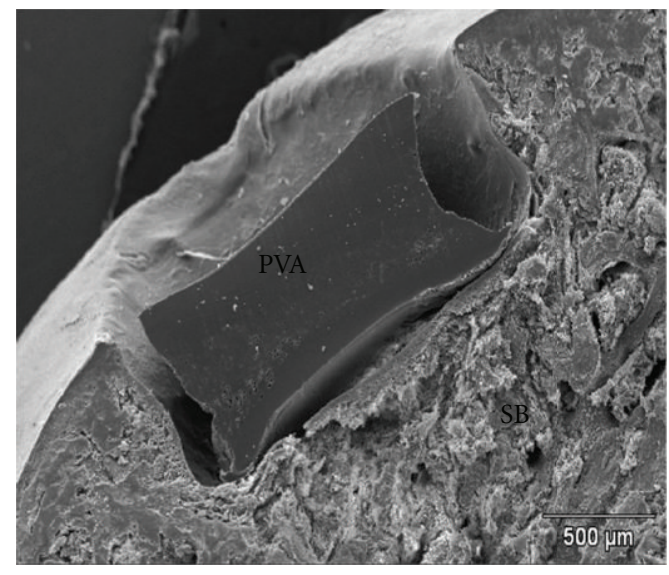

(b)



(c)

FIGURE 7: Scanning electron microscopy of the PVA surface in the condyle. (a) Scanning electron microscopy of the PVA interface of the osteochodral defect. (b) Histological section of the condyle-*observe absence of PVA which was removed during the treating process for histological analyses. (c) HE Staining 25x.

TABLE 2: Percentage of the results according to criteria and attributed the scores.

\begin{tabular}{|c|c|c|c|c|}
\hline & Scor & ps (EGs) & & \\
\hline & absent $(+) n$ & intensive (- & & \\
\hline Fyaluntion criteria & & Intensi & ace (\%) & \\
\hline Evaluation criteria & EG03 & EG06 & EG12 & EG24 \\
\hline & $83(+)$ & $83(+)$ & $73(+)$ & \\
\hline Granulation tissue (GI) & $17(++)$ & $17(++)$ & $27(++)$ & $100(+)$ \\
\hline Collagen fibers (CF) & $\begin{array}{c}50(++) \\
50(+++)\end{array}$ & $\begin{array}{c}3(+) \\
17(++)\end{array}$ & $\begin{array}{l}91(++) \\
9(+++)\end{array}$ & $\begin{array}{c}37,5(+) \\
50(++) \\
12,5(+++)\end{array}$ \\
\hline Mineralized bone matrix (MB) & $17(+)$ & $17(+)$ & $27(++)$ & $50(++)$ \\
\hline vimeramzed oome mathx (IVD) & $83(++)$ & $83(++)$ & $73(+++)$ & $50(+++)$ \\
\hline Neoformed bone tissue (NB) & $\begin{array}{c}17(+) \\
83(++)\end{array}$ & $\begin{array}{c}25(+) \\
50(++) \\
25(+++)\end{array}$ & $\begin{array}{c}45(++) \\
55(+++)\end{array}$ & $\begin{array}{c}62,5(+) \\
25(++) \\
12,5(+++)\end{array}$ \\
\hline Collapse of neoformed tissue $(\mathrm{CN})$ & $100(+)$ & $100(+)$ & $100(+)$ & $100(+)$ \\
\hline
\end{tabular}




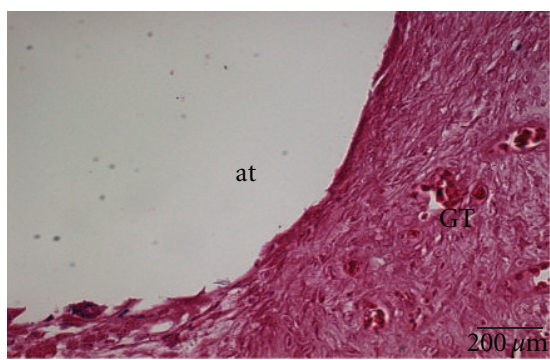

(a)

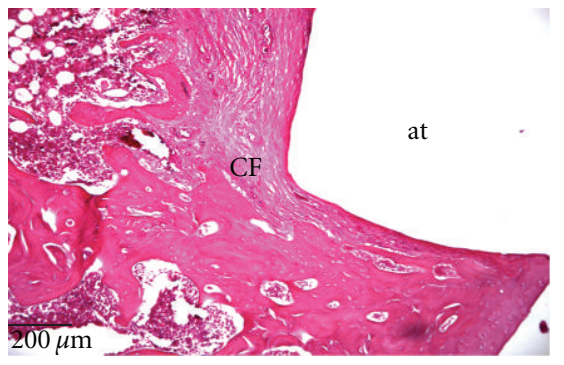

(b)

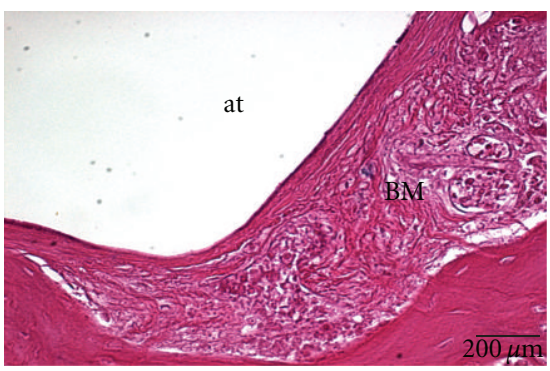

(c)

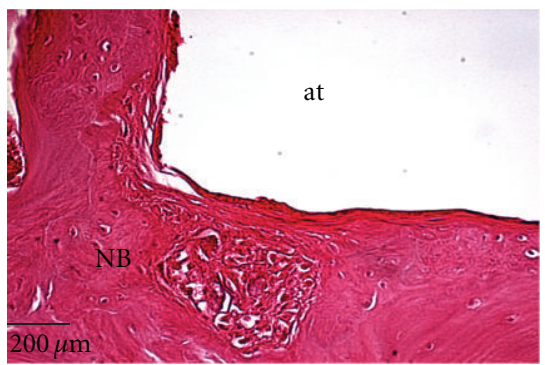

(d)

FIGURE 8: Longitudinal sections of samples containing the PVA implants. (a) EG03-presence of granulation tissue (GT); (b) EG06presence of collagen fibers (CF); (c) EG12-presence of mineralized bone matrix (BM); (d) EG24-presence of neoformed bone tissue $(\mathrm{NB})$. at = absence of tissue over the implant surface. Stained with Hematoxylin and Eosin.

3.2. X-Ray Fluorescence Analysis (EDXRF). Figure 5 shows the average concentrations of calcium, phosphorus and sulfur according to follow-up time.

3.3. Optical Macroscopy and Microscopy (OM). Figure 6 containing macroscopic images of EGs after animals were sacrificed.

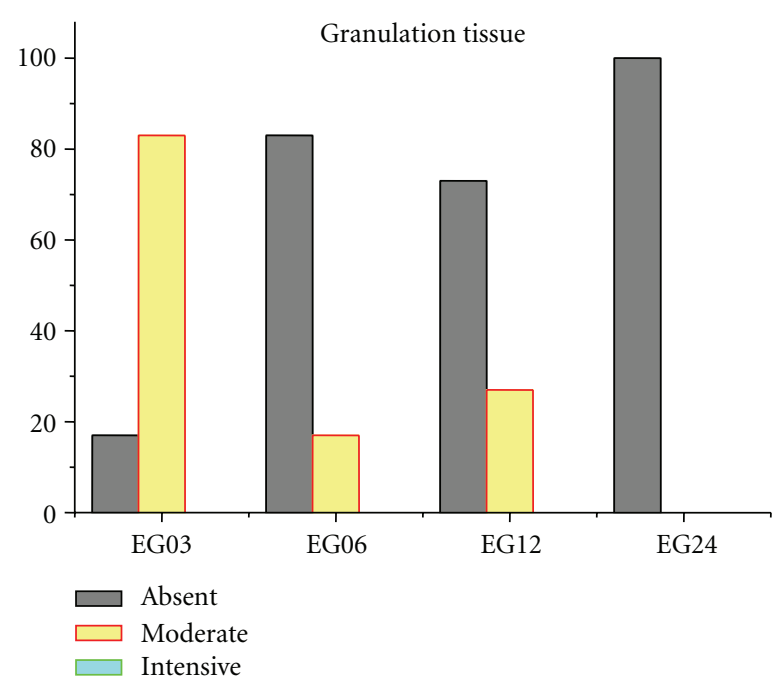

Figure 9: Mean granulation tissue in EGs samples. A 68\% absence and $32 \%$ moderate presence was observed, however intensive presence was not observed in any of the EGs.

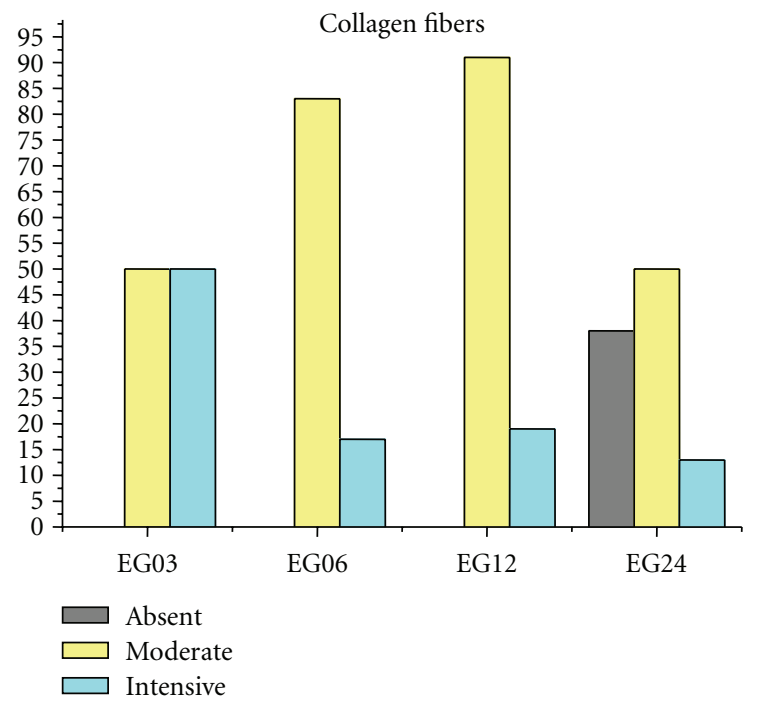

FIGURE 10: Mean EGs collagen fibers. Absence: 9\%, moderate: 69\%, and intensive: $22 \%$.

According to Mow et al. [4] implants, although inert when implanted, are involved by a fibrous capsule of connective tissue. In this study, this was confirmed by the absence of tissue formation on the PVA, as observed (Figure 7).

Figure 8 shows images obtained by OM. As can be noticed, the implant was removed from all samples during the processing for histological analysis. This occurred as there was no tissue growth over the implant surface.

Figures $9,10,11,12$, and 13 present mean scores obtained according to the criteria established in Table 2, these scores were given according to absence, moderate, or intensive presence of tissue on EGs according to duration of followup. 


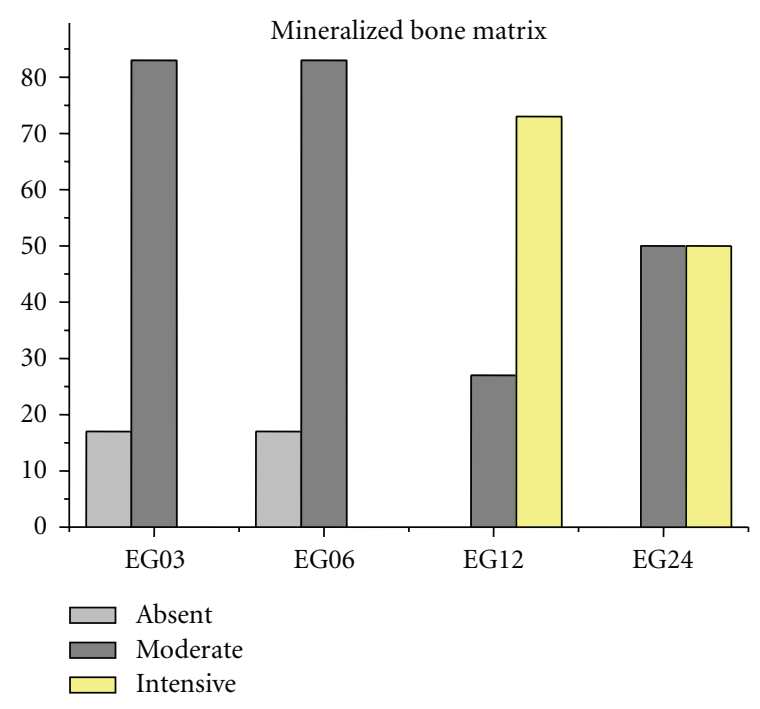

Figure 11: Mineralized bone matrix mean of EGs. Absence: 9\%, moderate: $61 \%$, and intensive: $30 \%$.

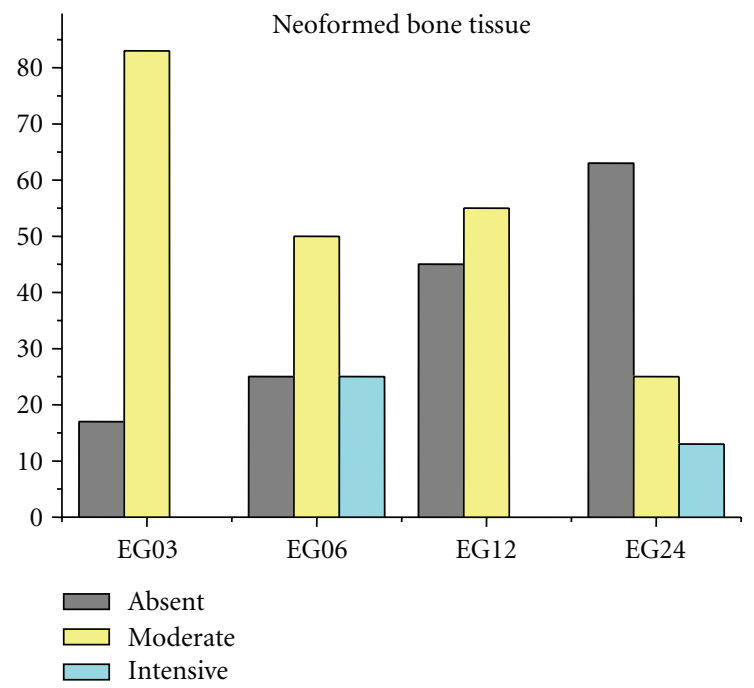

Figure 12: Mean neoformed bone tissue of EGs. Absence: 37\%, moderate presence: $53 \%$, and intensive presence: $10 \%$.

\section{Discussion}

Several studies have shown that the mechanical behaviors of the articular cartilage under in vitro and in vivo compression cannot be compared with each other. Contrary to in vitro, in vivo tissue recovers its original dimensions after load removal thanks to a number of factors that define the elasticity and water absorption capacity of its complex structure, such as pressure, viscosity, temperature and macromolecular content of the interstitial fluid, and the concentration and type of dissolved ions $[1,3,4]$.

Figure 4 clearly shows that the average creep modulus of the implanted hydrogels increased over time. The increase can be partially attributed to the regrowth of the subchondral bone at the defective bottom (Figures 6 and 7), which

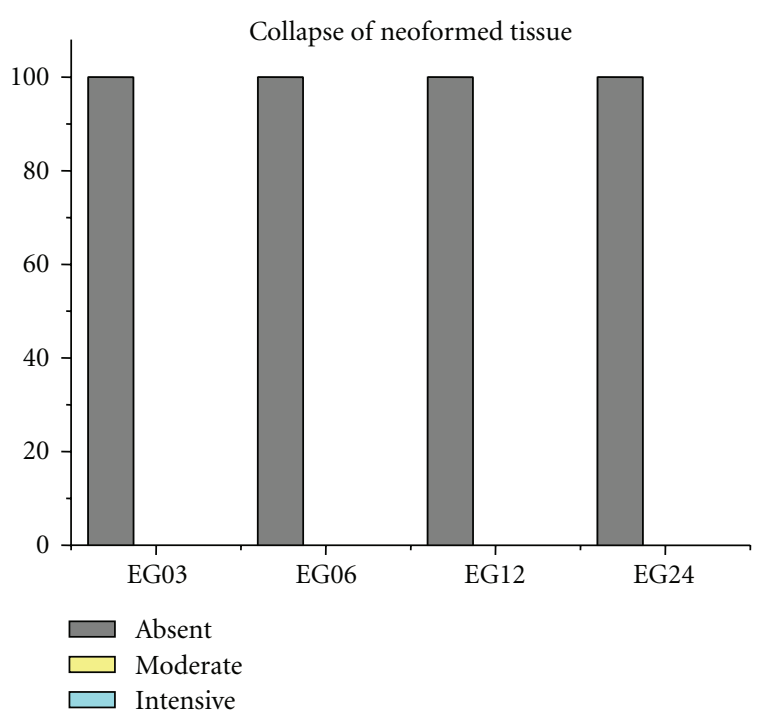

Figure 13: EGs collapse of neoformed tissue was 100\% absent in samples.

provided a stiffer bed for the implant over time, thus restricting deformation and resulting in a higher calculated creep modulus.

Comparing the creep modulus obtained in this study for rat cartilage (Figure 4) and that obtained by Kempson et al. [34] for human femoral cartilage (8.4-10.6 MPa), the values obtained for the PVA hydrogel, though relatively low, were still within the same order of magnitude.

Another contribution to the increase of the creep modulus over time could be assigned to the absorption of calcium and phosphorus by the implant, evidenced by the results of the EDXRF analysis (Figure 5).

The EDRFX analysis (Figure 5) revealed increasing concentrations of $\mathrm{Ca}$ and $\mathrm{P}$ in the implants over time, probably due to absorption of calcium phosphate, and a steady concentration of S in comparison to the GC00 (not implanted). The consequences of the absorption of calcium phosphate are still unclear and deserve further investigations. It is well known that all implants, although inert when implanted, are involved by fibrous capsule of connective tissue [4].

EDRFX results indicated an increase in $\mathrm{Ca}$ and $\mathrm{P}$ levels over follow-up time. Further studies are being carried out to determine if the analyzed elements were detected in or on the surface the PVA.

According to the macroscopic results of the EGs (Figure 6), the integrity of the surface of PVA and adjacent CA were maintained by the normal lubrication process.

As observed in the macroscopic images (Figures 7(a) and 7(b)), the PVA implant kept its integrity, with no sign of wear, in all EGs and in the adjacent CA. The result indicates that the process of synovial fluid lubrication was maintained during the entire followup.

From the OM (Figure 8), the quality of the interface between implant and the surrounding tissue (subchondral bone) was satisfactory, with no foreign body reaction. The PVA hydrogel could bear the load without rupture or 
wear and offered a suitable and stable environment for the formation of new bone at the interface with the host tissue.

The implant surface appears to have maintained its integrity due to the presence of synovial fluid. That was possible because the electron beam crosslinking of the PVA promoted the formation of a polymeric structure that was strong, yet still complacent and capable of absorbing and retaining synovial fluid, which kept low the friction between the articular surfaces and counter surfaces in all EGs.

The absence of signs of implant rejection in almost all samples attests the good compatibility between the hydrogel and the tissues surrounding the artificial osteochondral defect (Figures 9-13).

\section{Conclusion}

The PVA hydrogel implant bore the load without wear or rupture, offered a stable and suitable environment for growing new bone at the interface with the host tissue, and did not disturb the natural articular lubrication. The results of these mechanical, chemical, and histological analyses indicate PVA hydrogel irradiated and acetalised as a promising biomaterial for repairing osteochondral defects.

\section{Conflicts of Interests}

The authors declare that they have no conflict of interests.

\section{Acknowledgments}

This work is supported by CNPq Processes 485870/2007-0 and 574058/2008-7, INCT BIOFABRIS, Laboratory of Spectrometry IQM, and Laboratory of Physical Metallurgy and Solidification FEM.

\section{References}

[1] H. J. Mankin, H. Dorfman, L. Lippiello, and A. Zarins, "Biochemical and metabolic abnormalities in articular cartilage from osteo-arthritic human hips. II. Correlation of morphology with biochemical and metabolic data," Journal of Bone and Joint Surgery A, vol. 53, no. 3, pp. 523-537, 1971.

[2] H. Mankin, V. C. Mow, J. A. Buckwalter, J. P. Iannotti, and A. Ratcliffe, "Articular cartilage structure, composition and function," in Orthopaedic Basic Science: Biology and Biomechanics of the Musculoskeletal System, J. A. Buckwalter, T. A. Einhorn, and S. R. Simon, Eds., p. 443, American Academy of Orthopaedic Surgeons, 2000.

[3] D. Barnewitz, M. Endres, I. Krüger et al., "Treatment of articular cartilage defects in horses with polymer-based cartilage tissue engineering grafts," Biomaterials, vol. 27, no. 14, pp. 2882-2889, 2006.

[4] V. C. Mow, M. H. Holmes, and W. M. Lai, "Fluid transport and mechanical properties of articular cartilage: a review," Journal of Biomechanics, vol. 17, no. 5, pp. 377-394, 1984.

[5] G. M. Peretti, A. Pozzi, R. Ballis, D. Deponti, and F. Pellacci, "Current surgical options for articular cartilage repair," Acta Neurochirurgica. Supplement, vol. 108, pp. 213-219, 2011.

[6] W. W. Curl, J. Krome, E. S. Gordon, J. Rushing, B. P. Smith, and G. G. Poehling, "Cartilage injuries: a review of 31,516 knee arthroscopies," Arthroscopy, vol. 13, no. 4, pp. 456-460, 1997.
[7] A. E. Beris, M. G. Lykissas, C. D. Papageorgiou, and A. D. Georgoulis, "Advances in articular cartilage repair," Injury, vol. 36, no. 4, supplement, pp. S14-S23, 2005.

[8] E. B. Hunziker, "Articular cartilage repair: basic science and clinical progress. A review of the current status and prospects," Osteoarthritis and Cartilage, vol. 10, no. 6, pp. 432-463, 2002.

[9] L. L. Johnson, "Arthroscopic abrasion arthroplasty historical and pathologic perspective: present status," Arthroscopy, vol. 2, no. 1, pp. 54-69, 1986.

[10] J. A. Stammen, S. Williams, D. N. Ku, and R. E. Guldberg, "Mechanical properties of a novel PVA hydrogel in shear and unconfined compression," Biomaterials, vol. 22, no. 8, pp. 799-806, 2001.

[11] P. C. Kreuz, S. Müller, C. Ossendorf, C. Kaps, and C. Erggelet, "Treatment of focal degenerative cartilage defects with polymer-based autologous chondrocyte grafts: four-year clinical results," Arthritis Research and Therapy, vol. 11, no. 2, article R33, 2009.

[12] K. Mithoefer, T. R. McAdams, J. M. Scopp, and B. R. Mandelbaum, "Emerging options for treatment of articular cartilage injury in the athlete," Clinics in Sports Medicine, vol. 28 , no. 1 , pp. 25-40, 2009.

[13] R. J. Williams and S. C. Gamradt, "Articular cartilage repair using a resorbable matrix scaffold," Instructional Course Lectures, vol. 57, pp. 563-571, 2008.

[14] L. Hangody, G. Kish, Z. Kárpáti, I. Szerb, and I. Udvarhelyi, "Arthroscopic autogenous osteochondral mosaicplasty for the treatment of femoral condylar articular defects: a preliminary report," Knee Surgery, Sports Traumatology, Arthroscopy, vol. 5, no. 4, pp. 262-267, 1997.

[15] L. Hangody and P. Füles, "Autologous osteochondral mosaicplasty for the treatment of full-thickness defects of weightbearing joints: ten years of experimental and clinical experience," Journal of Bone and Joint Surgery A, vol. 85, no. 1, pp. 25-32, 2003.

[16] M. Brittberg, A. Lindahl, A. Nilsson, C. Ohlsson, O. Isaksson, and L. Peterson, "Treatment of deep cartilage defects in the knee with autologous chondrocyte transplantation," The New England Journal of Medicine, vol. 331, no. 14, pp. 889-895, 1994.

[17] I. Martin, D. Schaefer, and B. Dozin, Repair of Osteochondral Lesions, Bookshelf, 2008.

[18] K. Rezwan, Q. Z. Chen, J. J. Blaker, and A. R. Boccaccini, "Biodegradable and bioactive porous polymer/inorganic composite scaffolds for bone tissue engineering," Biomaterials, vol. 27, no. 18, pp. 3413-3431, 2006.

[19] J. R. Jones, L. M. Ehrenfried, and L. L. Hench, "Optimising bioactive glass scaffolds for bone tissue engineering," Biomaterials, vol. 27, no. 7, pp. 964-973, 2006.

[20] C. Liu, C. Gong, Y. Pan et al., "Synthesis and characterization of a thermosensitive hydrogel based on biodegradable amphiphilic PCL-Pluronic (L35)-PCL block copolymers," Colloids and Surfaces A, vol. 302, no. 1-3, pp. 430-438, 2007.

[21] S. H. Barbanti, C. A. C. Zavaglia, and E. A. R. Duek, "Polímeros Bioreabsorvíveis na Engenharia de Tecidos," Polimeros, vol. 15, pp. 13-21, 2005.

[22] V. P. Bavaresco, L. Garrido, N. A. Batista, S. M. Malmonge, and W. D. Belangero, "Mechanical and morphological evaluation of osteochondral implants in dogs," Artificial Organs, vol. 32, no. 4, pp. 310-316, 2008.

[23] N. A. Batista, Evaluation Behavior Polyvinyl Alcohol (PVA) Hydrogel Acetalized and Irradiated as Substitute of Articular Cartilage Implanted in Wistar Hannover Rat Knees, Unicamp, 2011. 
[24] A. N. Suciu, T. Iwatsubo, M. Matsuda, and T. Nishino, "A study upon durability of the artificial knee joint with PVA hydrogel cartilage," JSME International Journal C, vol. 47, no. 1, pp. 199-208, 2004.

[25] C. H. Cho, T. Murakami, Y. Sawae et al., "Elasto-plastic contact analysis of an ultra-high molecular weight polyethylene tibial component based on geometrical measurement from a retrieved knee prosthesis," Proceedings of the Institution of Mechanical Engineers H, vol. 218, no. 4, pp. 251-259, 2004.

[26] M. Oka, K. Ushio, P. Kumar et al., "Development of artificial articular cartilage," Proceedings of the Institution of Mechanical Engineers H, vol. 214, no. 1, pp. 59-68, 2000.

[27] Y. Sawae, T. Murakami, H. Higaki, and S. Moriyama, "Lubrication property of total knee prostheses with PVA hydrogel layer as artificial cartilage," JSME International Journal C, vol. 39, no. 2, pp. 356-364, 1996.

[28] M. Kobayashi, Y. S. Chang, and M. Oka, "A two year in vivo study of polyvinyl alcohol-hydrogel (PVA-H) artificial meniscus," Biomaterials, vol. 26, no. 16, pp. 3243-3248, 2005.

[29] V. P. Bavaresco, Estudo Tribológico de hidrogéis poliméricos para serem utilizados como cartilagem articular artificial [Ph.D. thesis], University of Campinas, Campinas_SP, Brazil, 2004.

[30] Z. Q. Gu, J. M. Xiao, and X. H. Zhang, "Development of a kind of artificial articular cartilage-PVA-hydrogel," Journal of Biomedical Engineering, vol. 16, no. 1, pp. 13-18, 1999.

[31] A. A. Rodrigues, N. A. Batista, V. P. Bavaresco et al., "Polyvinyl alcohol associated with carbon nanotube scaffolds for osteogenic differentiation of rat bone mesenchymal stem cells," Carbon, vol. 50, no. 2, pp. 450-459, 2012.

[32] A. A. Rodrigues, N. A. Batista, V. P. Bavaresco et al., "In vivo evaluation of hydrogels of polyvinyl alcohol with and without carbon nanoparticles for osteochondral repair," Carbon, vol. 50, no. 6, pp. 2091-2099, 2012.

[33] S. M. Malmonge, C. A. C. Zavaglia, and W. D. Belangero, "Biomechanical and histological evaluation of hydrogel implants in articular cartilage," Brazilian Journal of Medical and Biological Research, vol. 33, no. 3, pp. 307-312, 2000.

[34] G. E. Kempson, M. A. R. Freeman, and S. A. V. Swanson, "The determination of a creep modulus for articular cartilage from indentation tests on the human femoral head," Journal of Biomechanics, vol. 4, no. 4, pp. 239-250, 1971.

[35] R. Jekkings and J. L. de Vries, Practical X-Ray Spectrometry, Springer, New York, NY, USA, 2nd edition, 1970.

[36] J. W. Criss and L. S. Birks, "Calculation methods for fluorescent X-ray spectrometry: empirical coefficients versus fundamental parameters," Analytical Chemistry, vol. 40, no. 7, pp. 1080-1086, 1968. 



The Scientific World Journal

Submit your manuscripts at

http://www.hindawi.com

\section{World Journal}



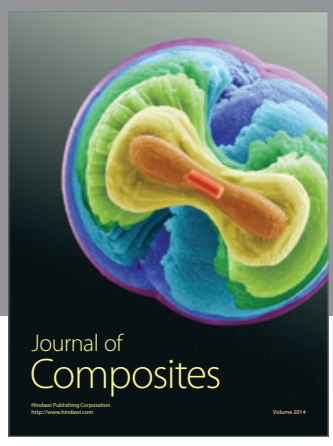
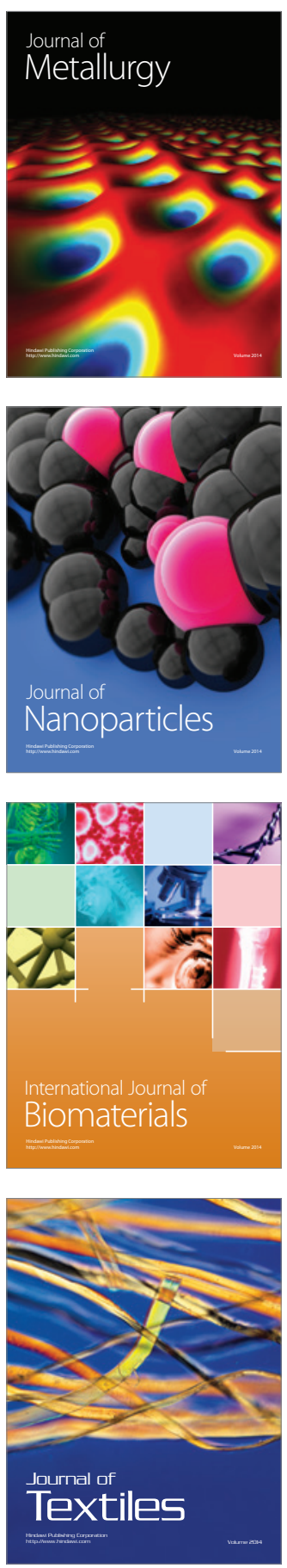